\title{
2 DOCTOR OF PHILOSOPHY, HEAL THYSELF
}

\author{
Allen S. Lee \\ Virginia Commonwealth University
}

\begin{abstract}
As doctors of philosophy who are specialists in information systems, we routinely perform diagnoses of, and write prescriptions for, individuals, groups, organizations, societies, and their artifacts. The proverb "physician, heal thyself" requires that we ourselves, along with our scholarly artifacts, societies, organizations, and groups, undergo the same manner of diagnosis to which we subject others, and that we have a taste of our own medicine. This essay uses three published papers of Working Group 8.2 of the International Federation for Information Processing - from the 1984 Manchester meeting, from the 1990 Copenhagen meeting, and from the 1997 Philadelphia meeting - as a source of rich material with which to illustrate the difference in our diagnoses and prescriptions if we were to do unto ourselves what we do unto others.
\end{abstract}

\section{INTRODUCTION}

We are doctors of philosophy who are specialists in information systems. In this role we perform diagnoses of, and we write prescriptions for, individuals, groups, organizations, societies, and their artifacts. At the same time we need to ask ourselves: Must we practice what we preach? Must we ourselves, along with our scholarly artifacts, societies, organizations, and groups, undergo the same manner of diagnosis to which we subject others, and must we have a taste of our own medicine? The answer is that we must: We doctors of philosophy may not exempt ourselves from our own scrutiny or our own medicine-lest we violate the scientific requirement of consistency in our research and the ethical requirement of the golden rule in our conduct.

Some might argue that our research has indeed been inconsistent and our conduct hypocritical. It can appear that we doctors of philosophy readily and routinely train a critical eye on others, but not ourselves. Others might argue that a finding of inconsistency and hypocrisy is premature. There is no a priori reason that the optimal or only 
time to begin diagnosing and prescribing for ourselves is already in the past. And because the discipline of information systems is, at most, 50 years old, one can also argue that the information systems discipline is ready, only now, to turn a critical eye on itself.

Although sharing a specialty in information systems, we doctors of philosophy are a diverse lot. Mirroring the diversity among ourselves is the diversity of the research that we publish in our journals, such as European Journal of Information Systems, Information Systems Research, Information Systems Journal, and MIS Quarterly. Of the many different segments of our information systems research community, one that offers itself as especially promising material for a revelatory case study is the one that calls itself Working Group 8.2 of the International Federation for Information Processing. Given its self-conscious and reflective stance on research methods and its comfort with critical social theory, Working Group 8.2 is more likely than any other segment of the information systems research community to be able to understand the scientific and ethical necessity to heal itself and not just others. If the case cannot be made that we doctors of philosophy of WG 8.2 are ready, willing, and able to do unto ourselves what we have been doing unto others, then there would be little hope that the same case can be made for the information systems research community overall.

WG 8.2 's self-conscious and reflective nature has long been evident in its existence and has manifested itself in the form of a persistent concern over research methods. Not only does the topic of research methods provide the theme for the current conference in Manchester, but it was also the theme for three of WG 8.2's past conferences-1997 in Philadelphia, 1990 in Copenhagen, and in 1984, also in Manchester. WG 8.2 's regularly recurring reflection on research methods is a manifestation of its awareness of and sensitivity to the process of scientific research, apparently seen as distinct from, and no less important than, any content that the process produces. ${ }^{1}$ In this light, if there are any doctors of philosophy in the overall information systems research community who are ready, willing, and able to do unto themselves what they do unto others, they are likely to be found among the doctors of philosophy in WG 8.2.

The following argument examines three past instances in which WG 8.2 focused on diagnosing and prescribing for others, and also what would have been different in these instances if WG 8.2 had focused, in addition, on diagnosing and prescribing for itself. This difference will serve to illustrate what we-people who are members of the 8.2 community and the information systems discipline overall-can do to practice what we preach, with the result that we can satisfy both the scientific requirement of consistency in our research and the ethical requirement of the golden rule in our conduct. The argument will begin with a fundamental point from Thomas Kuhn's history of science - that a community of scientific researchers has, and is shaped by, its own sociology, not unlike any other community that these researchers themselves would typically investigate.

1، A great deal hinges on whether science is viewed as a body of propositions or as the enterprise in which they are generated, as product or as process" (Kaplan 1964, p. 7). At the same time, no choice need be made. Science can be viewed as both process and product. Arguably, viewing it as process is more important because science as product is determined by science as process. 


\section{SCIENTIFIC RESEARCHERS ARE RESEARCH SUBJECTS TOO}

Kuhn's Structure of Scientific Revolutions (1996) and his related studies are instances of research in history and sociology. In his empirical, historical investigation of natives who called themselves "scientists"-including those who called themselves physicists and biologists and whose shared cultural beliefs, rituals, politics, and superstitions are fascinating but beyond the scope of this single paper to examine-Kuhn often refers to their sociology. One example is

Some of the principles deployed in my explanation of science are irreducibly sociological, at least at this time. In particular, confronted with the problem of theory-choice, the structure of my response runs roughly as follows: take a group of the ablest available people with the most appropriate motivation; train them in some science and in the specialties relevant to the choice at hand; imbue them with the value system, the ideology, current in their discipline (and to a great extent in other scientific fields as well); and finally, let them make the choice. If that technique does not account for scientific development as we know it, then no other will. There can be no set of rules of choice adequate to dictate desired individual behaviour in the concrete cases that scientists will meet in the course of their careers. Whatever scientific progress may be, we must account for it by examining the nature of the scientific group, discovering what it values, what it tolerates, and what it disdains.

That position is intrinsically sociological...(Kuhn 1970, pp. 237-238).

In examining scientists in this way, Kuhn is casting them in the role of research subjects and, therefore, rendering them as objects of study.

One can argue that if physicists have a sociology, then other researchers do too. Accepting the generalization that the people who call themselves social scientists and information systems researchers are themselves research subjects similarly to how the self-proclaimed natural scientists are research subjects, we may conclude that the former are no more immune to sociological, historical, and other scientific investigation than any other natives.

In some of our past annual meetings, we members of a society which we call 8.2 have offered research methods and perspectives for how we would diagnose, and prescribe for, others-in particular, people in the midst of their organization, their organization's information technology, and the many phenomena emerging from the mutually transforming interactions between the organization and the information technology. In what follows, there are three instances of research methods or research perspectives that members of 8.2 have entertained in presentations at their earlier conferences. I have chosen the three papers so as to represent each of the earlier three meetings, as well as to include authors whose prominence, recognition, and active research programs extend to the present. Following each instance, in turn, is a scenario for how- if ready, willing, and able-we members of WG 8.2 or the information systems research community overall could likewise diagnose and prescribe for ourselves. The examples build on earlier ones (Lee 2000) and are in keeping with their spirit. 


\subsection{Three Knowledge Interests for Information Systems Đevelopment Information Systems Research and Publishing}

As early as at its 1984 meeting in Manchester, WG 8.2 recognized and embraced critical theory. Lyytinen and Klein (1985) introduced the critical theory of Jürgen Habermas to WG 8.2. The following passage from their paper well conveys its overall spirit and identifies some ramifications of critical social theory for how information systems researchers diagnose and prescribe for information systems development (pp. $225-226) .^{3}$

The Implications of Three Knowledge Interests for Information Systems Development

Because information systems development is currently dominated by approaches based on the idea of purposive-rational action, the underlying knowledge basis of many of its methodologies is [the] technical knowledge interest. This appears to be true even of those methodologies which take a broader social perspective such as socio-technical system approaches and implementation research. Variations can only be found in the scope of inquiry, its conceptual basis and applied inquiring methods.

Our understanding of the process and content of information systems development and its supporting methodologies can be improved considerably if it is recognized that it includes not only [the] technical knowledge interest, but also practical and emancipatory knowledge interests.

First, restricting attention to [the] technical knowledge interest influences how problems are defined and understood. They are perceived as given and as totally independent of the investigator. Because of this narrow focus, methodologies are unable to explain how people, through social learning, create new meanings and concepts to cope with new situations.

Second, a concentration on technical knowledge interests conceals the real processes of information systems development and their dependency on communicative action. In the majority of information systems design methodologies, design groups see users as "producers of information," as "primary problem solvers" and as "opponents in an implementation game." Information systems development as a process of communicative action through ordinary language is hardly known and rarely studied. In consequence, methods to assist the sharing of different opinions and problems, and the role of ordinary lan-

${ }^{2}$ The use of strike-outs, followed by italicized words replacing the stricken words, is intentional. As the subsequent text will make clear, I use it to indicate how I am mapping lessons about people, organizations, and information technologies from each of the three earlier 8.2 papers to the current situation of ourselves as researchers regarding our own information technology (i.e., research methods) and our own organization (i.e., our 8.2 community).

${ }^{3}$ The citations in the quoted materials are suppressed. 
guage in this process, have not been developed and studied. Because of this, most methodologies cannot handle the participation issue or examine it theoretically.

Third, existing methodologies appeal to value-neutrality and instrumental reason. They define all information systems problems in terms of means and ends, and the most efficient way of pursuing these. This selecting implies a tyranny of means over ends. There is little consideration of values and goals, and the design process is seen as "an act of faith." There is no attempt to legitimate goals through developing a rationally grounded consensus among the stakeholders.

Lyytinen and Klein's use of critical theory to diagnose and prescribe for information systems development is also suggestive of how they and other information systems researchers can use critical theory to diagnose and prescribe for themselves and their work (i.e., information systems research). Consider

The Implications of Three Knowledge Interests for Information Systems Đevetopment Information Systems Research and Publishing

Because information systems development information systems research and publishing is currently dominated by approaches based on the idea of purposive-rational action, the underlying knowledge basis of many of its methologies the methods used in information systems research is [the] technical knowledge interest. This appears to be true even of those methodotogies research methods which take a broader social perspective such as those used in socio-technical system approaches and implementation research. Variations can only be found in the scope of inquiry, its conceptual basis and applied inquiring methods.

Our understanding of the process and content of forms development information systems research and publishing and its supporting methodologies research methods can be improved considerably if it is recognized that it includes not only [the] technical knowledge interest, but also practical and emancipatory knowledge interests.

First, restricting attention to [the] technical knowledge interest influences how research problems are defined and understood. They are perceived as given to the information systems researcher by what the research discipline itself (its literature, its journals, its conferences) considers to be significant research and as totally independent of the investigator. Because of this narrow focus, methologies research methods are unable to explain how people information systems researchers, through social learning, create new meanings and concepts to cope with new situations.

Second, a concentration on technical knowledge interests conceals the real processes of information systems research and publishing and their dependency on communicative action. In the majority of information systems design methodologies research methods, design groups see users editors and reviewers see researchers as "producers of information" 
and as "primary problem solvers" while researchers see editors and reviewers as "opponents in the publication game." Information systems research and publishing as a process of communicative action through ordinary language is hardly known and rarely studied. In consequence, methods to assist the sharing of different opinions and problems among information systems researchers, and the role of ordinary language in this process, have not been developed and studied. Because of this, most methologies research methods cannot handle the partieipation isste research-and-publication process or examine it theoretically.

Third, existing methodologies research methods appeal to value-neutrality and instrumental reason. They define all information systems research problems in terms of means and ends, and the most efficient way of pursuing these. This selecting implies a tyranny of means over ends. There is little consideration of values and goals of the information systems researchers, and the research-and-publication process is seen as "an act of faith." There is no attempt to legitimate research goals through developing a rationally grounded consensus among the stakeholders, who include researchers, editors, reviewers, tenure-and-promotion committees, and research funding agencies.

The above rendering of "The Implications of Three Knowledge Interests for Information Systems Development" into "The Implications of Three Knowledge Interests for Information Systems Research and Publishing" is not a determinative mapping of features from one domain to another, but just one possible way of suggesting similarities between the two domains. Just as diagnosing and prescribing occur in the former, they can occur in the latter. Other possible renderings would lead to the same conclusion, which is that we, as information systems researchers, have much work remaining to be done in diagnosing ourselves as researchers, as well as prescribing what we should be doing, or doing better, in the research-and-publication process of our information-systems research community.

\subsection{Information Systems Use Information Systems Research and Publishing as a Hermeneutic Process}

A trait of WG 8.2 that has distinguished it within the information systems research community is its singular devotion to qualitative research, particularly interpretive research. An interpretive approach that has received much attention from 8.2 members is hermeneutics. At the 1990 meeting of 8.2 in Copenhagen, Boland (1991) presented a paper on, among other things, the hermeneutic interpretation of accounting data. Boland offered the following conclusion about information systems use as a hermeneutic process (p. 454).

Viewing information system use as a hermeneutic process opens a new set of research concerns. From a hermeneutic view, attention would shift from how well an information system represented a situation to how well it enabled the reader to appropriate possibilities for being within the situation and themselves. 
Attention would shift from identifying the user's essential, foundational and enduring set of information needs to identifying how different information availability enabled the juxtaposition of quantity and quality, the shifting back and forth from numbers and calculation to persons and values. Attention would shift from the information systems as a device for data output to the information system as an environment for acting out interpretations - a space for actively appropriating meaning about our situations and ourselves.

It is an easy step from Boland's prescription of hermeneutics for viewing information systems use to the same or same-styled prescription of hermeneutics for viewing information systems research.

Viewing informationsystemuse information systems research and publishing as a hermeneutic process opens a new set of research concerns. From a hermeneutic view, attention would shift from how well an informationsystem represented information systems research represents, explains, or interprets a situation to how well it enabled the reader enables information systems researchers to appropriate possibilities for being within the situation researchand-publication process and being themselves. Attention would shift from identifying the tser's researcher's essential, foundational and enduring set of information neets needs regarding theory and data to identifying how different information different research methods enabled could enable the juxtaposition of quantity and quality positivist research and interpretive research, the shifting back and forth from numbers and ealeutation survey, field, experimental, or archival data and data analysis to the researchers themselves and their values. Attention would shift from the information systems as a device for data output information systems research as a process for developing theory about people and technologies that we researchers observe in organizational settings to the information system information systems research as additionally involving a parallel process in which we researchers strive to engage in research as a meaningful and rewarding activity unto itself, that is, as an environment for acting out interpretations of the social, political, technological, and even scholarly dimensions that both enrich and diminish us in the day-to-day work that we do as researchers and that allow us to enjoy being ourselves - a space for actively appropriating meaning about our situations and ourselves.

Because we information systems researchers are people or research subjects no less than the people in organizations whom we observe, and because the research methods that we information systems researchers use are no less an information technology than the electronic information technologies that routinely interact with the people and organizations about whom we theorize (Lee 2003, pp. 312-314), the theories and methods that we researchers have already accumulated are also ready and available for us to use in diagnosing, and prescribing for, ourselves-including our own social, political, technological, and even scholarly activities. Furthermore, in a situation where the theories or methods of any of us researchers fail when applied to ourselves, the 
failure itself would constitute hard evidence unfavorable to the given theory or method and thereby contribute to invalidating it. In the process of further developing or otherwise improving the theory or method so that it might succeed instead of fail in this situation, we information systems researchers would be diagnosing shortcomings in our own activity of researching, as well as prescribing and taking remedies for how to overcome them.

\subsection{Researehron Practice Research on the Practice of Research}

At the 1997 meeting of 8.2 in Philadelphia, Markus gave the opening keynote address. She rightly noted the great progress in the development of qualitative research methods and their acceptance since the time of the 1984 meeting in Manchester (Markus 1997, p. 12).

As I look back over the proceedings of the Manchester and Copenhagen meetings and the research published in IS over the same time frame, it is clear to me that qualitative research has won at least one major championshipacademic acceptance, both within the IS field and within the larger domain of academic management studies. Today, most high-status members of the IS community acknowledge that qualitative research methods occupy an important niche along with formal modeling and quantitative empirical methods (survey and experiments). Qualitative studies and methodological essays dealing with qualitative methods increasingly appear in our conferences and journals. Some research articles employing qualitative methods figure among the seminal studies read by IS doctoral students. An increasing number of IS doctoral programs teach qualitative research methods and legitimize the use of qualitative methods in dissertation research. Further, members of our field whose work is largely or exclusively qualitative in methods have been granted promotion and tenure in their respective institutions, signifying that academics from other management disciplines also accept the legitimacy of qualitative IS research. Members of our field have been appointed to the editorial boards of journals in other fields. Other signs of acceptance can be noted.

Markus did not broach the possibility in which we qualitative information systems researchers would apply our increasingly accepted qualitative research methods in studies of ourselves and our research work, but she did acknowledge another area no less deserving of further, serious study, namely, practical research (p. 18).

A third new [arena] I think we should enter is the appreciation of practical knowledge.....By practical research, I mean academic research that seeks primarily to describe, qualify or measure, evaluate or interpret practice.. .I am deliberately contrasting practical research with theoretical research, which seeks primarily to build or test academic theory... .Therefore, by appreciation of practical research, I mean that we as an academic field should (collectively) 
consume, reward, and contribute more heavily to a literature about what is going on in practice than we do today.

She continued (p. 22)

If you agree that practical IS research fills important needs, you may still need to be convinced that it is something that we qualitative IS researchers should include in our portfolio of activities. I hardly need to convince you that this is something we can do: with some shift in mindset, perhaps, our methods are ideally suited to practical research. Instead, I'll try to show why we need to do it, because it requires skills we have and because it is something that no other group of professionals has the skills and incentives to do.

However, before plying our qualitative research skills in doing what Markus calls practical research, it would behoove us first to recognize that we, as researchers, are also practitioners, where we engage in the practice of research. To diagnose and prescribe for other practitioners, we would also need, eventually, to use our own methods to diagnose and prescribe for ourselves in our own roles as practitioners-i.e., practitioners of research. Ruling out the necessity of eventually diagnosing and prescribing for ourselves in our role as research practitioners would be as unscientific and unethical as ruling out this necessity in any of the other roles we play. If Markus were to agree with this conclusion, how might she suggest we proceed?

A third new [arena] I think we should enter is the appreciation of preat knowledge knowledge about the practice of research... By practical researeh research on the practice of research, I mean academic research that seeks primarily to describe, qualify or measure, evaluate or interpret practice the practice of research... I am deliberately contrasting praetieal researeh research on the practice of research with methodological research, which seeks primarily to develop research methods that research practitioners can use instrumentally to build or test academic theory....Therefore, by appreciation of praetieal researeh research on the practice of research, I mean that we as an academic field should (collectively) consume, reward, and contribute more heavily to a literature about what is going on in praetiee the practice of research than we do today....

If you agree that praetieal IS researeh research on the practice of IS research fills important needs, you may still need to be convinced that it is something that we qualitative IS researchers should include in our portfolio of activities. I hardly need to convince you that this is something we can do: with some shift in mindset, perhaps, our methods are ideally suited to praetieat researeh research on the practice of research. Instead, I'll try to show why we need to do it, because it requires skills we have and because it is something that no other group of professionals has the skills and incentives to do.

In the eyes of an anthropologist whose research subjects are the natives in a village who practice this or that craft, we information systems researchers would be these 
natives and our scientific research would be the craft that we, the natives, practice. In the same way that our information systems theories, shaped by our research methods, either bear or should be made to bear a diagnostic and prescriptive relationship to information systems practitioners and their craft, our information systems theories and methods either bear or should be made to bear a diagnostic and prescriptive relationship to ourselves and our craft of research. To proceed as the Markus-inspired text suggests would lead us, as researchers, not only to learn from undergoing the same manner of scrutiny with which we routinely diagnose IS practitioners, but also to learn from having a taste of the same medicine that our published research routinely dispenses under the heading of "ramifications for practitioners" or "recommendations for practice."

\section{READY, WILLING, AND ABLE}

The titles appearing in the table of contents of the anthology published for the current, 2004 meeting in Manchester would, in themselves, constitute telling signs of whether any doctors of philosophy in the information systems research community feel ready, willing, and able to heal ourselves. For example, instead of a title such as "The Critical Theory of Jürgen Habermas as a Basis for a Theory of Information Systems" (Lyytinen and Klein 1986) there would be "The Critical Theory of Jürgen Habermas as a Basis for a Theory of Information Systems Researchers"; instead of "Information Systems Use as a Hermeneutic Process" there might be "Information Systems Research and Publishing as a Hermeneutic Process"; and instead of "TheQualitative Difference in Information Systems Research and Practice" there would be, perhaps, "The Qualitative Difference in Information Systems Researchers and Practitioners." The absence of the latter sort of titles would provide a sign that we information systems researchers are not yet ready, willing, or able to diagnose and prescribe for ourselves as we have diagnosed and prescribed for others. However, if such titles were to appear, the results would be fascinating.

At the same time, it would not be appropriate to fault any current or past research article in our information systems discipline for not having pondered explicitly on our own praxis or for not having taken our own research methods in diagnosing and prescribing for ourselves. The unit of analysis or unit of action is not the individual research article. Every individual research article exists only in a larger context, and it is the context that would, or would not, make it conducive and feasible for an individual researcher to infuse the prescription, heal thyself, into the development and writing of his or her individual research article. Change must occur at institutional levels before, or concurrently with, change at the level of individuals, so as to set the stage for changes in the practice of research by individual researchers and the content of their individual research studies.

I foresee the needed change as unfolding concurrently in three processes. I am referring to the processes to which how Berger and Luckmann (1966, p. 61) refer when explaining their concept of the social construction of reality

- Society is a human product

- Society is an objective reality 
- Man is a social product

The three concepts refer respectively to the processes that Berger and Luckmann call externalization, objectivation, and internalization. We members of the 8.2 research community have already been applying these phenomenological or social-constructionist concepts in our research on people, organizations, and information technologies for years. Now, in applying the same concepts to ourselves, I argue

- Information systems research is a product of information systems researchers

- Information systems research itself is an objective reality

- An information systems researcher is a product of information systems research

These three concepts also refer respectively to the processes of externalization, objectivation, and internalization. This conceptualization of the social context in which a research article comes into being suggests that the prescription heal thyself ought to be diffused concurrently in (1) the process of externalization, in which information systems researchers produce information systems research and which involves not only individual-level activities such as a single researcher's work in crafting a dissertation or a submission to a journal, but also social-level activities such as the enactment of preexisting shared norms and practices (the research culture) in the manuscript review process or the tenure-and-promotion process; (2) the process of objectivation, in which information systems research that has already been produced comes to take a life of its own, continues to exist even when its authors leave the research community, and, like any other objective reality, conies to be accepted as "given" by new information systems researchers who encounter it for the first time; and (3) the process of internalization, in which information systems researchers (especially those newly entering the research community) learn and appropriate the given information systems research, as well as come to have their research thinking and research behaviors shaped by it. Until and unless such interventions occur, any attempt by an individual researcher to follow the prescription heal thyself in an individual research paper would be met with disapproval or misunderstanding from the overall community of information systems researcherswhether the individual researcher's effort were to involve the crafting of a new paper or the revision of an old one. In short, it is not only the individual researcher or individual research paper, but also the research context, that requires change and intervention.

What, precisely, might some helpful interventions in the three processes be? Being but an individual researcher existing in a larger research context, I alone cannot design and carry out any such intervention. However, if there happened to be a physical, sametime, same-place gathering of information systems researchers-including those who wield influence- these individuals and I could initiate a dialogue amongst ourselves, where we would conspire to design and carry out what we believe would be helpful interventions into our own research community. To this group, I would give a few examples, for illustrative purposes, of what the interventions could be.

Regarding the process of internalization, one possible starting point would be the developmental process by which information systems doctoral students become fully fledged information systems researchers. Just as people who study to become psycho- 
therapists often must undergo psychotherapy themselves as part of their education, doctoral students in information systems could undergo experiences as experimental subjects in positivist research and as organizational members in interpretive research where, of course, the research topic would fall in the domain of people, organizations, and information technologies. In their subsequent reading of the research write-up, the doctoral students could see and feel themselves objectified and they could assess the appropriateness or helpfulness of the practical recommendations given to them for how they may improve themselves and what they ought to do. In similar fashion, information systems researchers who are advisors and teachers of doctoral students could serve as research subjects in studies conducted by doctoral students (although, perhaps, not those from the same institutions as the advisors and teachers), where the information systems researchers could then ponder how they have been conceptualized (e.g., as effective or ineffective users of technology, or as actors who use technology to thwart the aspirations of other organizational members) as well as how appropriate and helpful they find the practical recommendations given to them.

Regarding the process of externalization, researchers could be given a particular setting in which they would feel safe to produce research that embodies specific aspects of the prescription heal thyself, such as those which I suggested above in my applications of ideas rooted in the works of Lyytinen and Klein, of Boland, and of Markus. One possibility would be for a safe context to be provided by Working Group 8.2 -i.e., a future conference that would accept papers that do such things as the following: It would be fascinating to attend the presentation of papers in which we 8.2 members (1) provide thick descriptions about what we have experienced as "intellectual and social domination" (Lyytinen and Klein 1985, p. 225), whether at the hands of the larger information systems research community or at the hands of other 8.2 members, (2) describe, in our own words, our "concern to have free, open communications and the conditions that enable these to take place" (Lyytinen and Klein 1985, p. 225) both within 8.2 and in the overall information systems research community, and (3) listen to ourselves describe what emancipation would mean for us if we were to say "The purpose of such inquiries is our emancipation" (Lyytinen and Klein 1985, p. 225). It would be fascinating to attend paper presentations and panel discussions in which we members of 8.2 describe our success or failure in shifting from a focus on how well our theory represents, explains, or interprets one or another situation of technology-organization interaction to a focus on how well the research-and-publication process enables us, as researchers, to appropriate possibilities for scholarly development and fulfillment within the research-and-publication process and for being our personal and professional selves (cf. Boland 1991, p. 454). It would be fascinating, even if only in the long run, to listen to an 8.2 keynote speaker proclaim that our reflective research, in which we doctors of philosophy diagnose and prescribe for ourselves so as to heal ourselves, "has won academic acceptance, both within the information-systems research community and within the larger domain of academic management studies" (Markus 1997, p. 12). Such papers could not simply be written and submitted to any information systems conference today with the expectation of being accepted. However, a conference of WG 8.2 dedicated to the theme of "Doctor of Philosophy, Heal Thyself" would provide a safe setting welcoming of such research. 
The process of objectivation would be largely the responsibility of those information systems researchers who wield influence as journal editors, conference program chairs, journal and conference reviewers, external reviewers in tenure-andpromotion cases, and highly respected members of our research community in general. It is these scholars of influence who determine the research papers and research ideas that are accepted and approved. It is also these scholars who determine the research papers to which subsequent papers must refer and cite. In this way, they are primarily responsible for selecting the research articles and books that come to endure and continue to shape future research, even when their authors cease doing research or otherwise leave the research community. One plausible setting in which these scholars may wield their influence would be a conference that they organize and whose theme would be "Doctor of Philosophy, Heal Thyself." As the organizers, program chairs, and reviewers serving this conference, they could explicitly solicit research on this theme, provide criteria by which such research submissions would be judged, and eventually encourage the further development of some of these papers for submission to mainstream information systems journals.

It is possible that we members of the information-systems research community do not yet feel ready, willing, and able to heal ourselves. However, there remains the entire future for us to prepare to feel this way. Perfection achieved today is always ideal, but progress will suffice-progress toward satisfying the scientific requirement of consistency in our research and the ethical requirement of the golden rule in our conduct.

\section{REFERENCES}

Berger, P. L., and Luckmann, T. The Social Construction of Reality: A Treatise in the Sociology of Knowledge, Garden City, NY: Doubleday, 1966

Boland, R. J. "Information System Use as a Hermeneutic Process," in H.-E, Nissen, H. K. Klein, and R. Hirshheim (Eds.), Information Systems Research: Contemporary Approaches \& Emergent Traditions, Amsterdam: North-Holland, 1991, pp. 439-464.

Kaplan, A. The Conduct of Inquiry, San Francisco: Chandler Publishing, 1964.

Kuhn, T. S. "Reflections on My Critics," in I. Lakatos and A. Musgrave (Eds.), Criticism and the Growth of Knowledge, London: Cambridge University Press, 1970, pp. 231-278.

Kuhn, T. S. The Structure of Scientific Revolutions ( $3^{\text {rd }}$ ed.), Chicago: University of Chicago Press, 1996.

Lee, A. S. "Building and Testing Theory on New Organizational Forms Enabled by Information Technology," in B. Sundgren, P. Mårtensson, M. Mähring, and K. Nilsson (Eds.), Exploring Patterns in Information Management: Concepts and Perspectives for Understanding ITRelated Change (Essays in Honor of Mats Lundeberg, Professor of Information Management), Stockholm: The Economic Research Institute, Stockholm School of Economics, 2003, pp. 305-320.

Lee, A. S. "Challenges to Qualitative Researchers in Information Systems," in E. M. Trauth (Ed.), Qualitative Research in Information Systems: Issues and Trends, Hershey, PA: Idea Group Publishing, 2000, pp. 240-270.

Lyytinen, K. J., and Klein, H. K. "The Critical Theory of Jürgen Habermas as a Basis for a Theory of Information Systems," in E. Mumford, R. Hirschheim, G. Fitzgerald, and A. T. Wood-Harper (Eds.), Research Methods in Information Systems, Amsterdam: NorthHolland, 1985, pp. 219-236. 
Markus, M. L. "The Qualitative Difference in Information Systems Research and Practice," in A. S. Lee, J. Liebenau, and J. I. DeGross (Eds.), Information Systems and Qualitative Research, London: Chapman \& Hall, 1997, pp. 11-27.

\begin{abstract}
ABOUT THE AUTHOR
Allen S. Lee a senior editor and former editor-in-chief of MIS Quarterly. He is professor of information systems and associate dean for research and graduate studies in the School of Business at Virginia Commonwealth University. Currently he is also a visiting professor at the London School of Economics and at Queen's University Belfast, and a visiting scholar at Indiana University. As a research methodologist, Allen has maintained a research stream on research approaches such as interpretivism, positivism, case studies, and action research. He served as a program chair for the 1997 meeting of IFIP WG 8.2 in Philadelphia and the general chair for the 2001 meeting of 8.2 in Boise.
\end{abstract}

